García, A. (2015) La danza folclórica en Bogotá: Cavilando reflexiones.

Calle14, 10 (16) pp. $30-39$

\title{
LA DANZA FOLKLÓRICA EN BOGOTÁ: CAVILANDO REFLEXIONES
}

\begin{abstract}
RESUMEN
La creación en la danza folklórica al parecer entra en estados continuos de resistencia. Fenómeno que esta adscrito a disociaciones generadas en la circulación de su significado como noción y también, a contradicciones que impregnan su praxis como género danzario. Atendiendo a esto, se pueden evidenciar ambigüedades entre concepto y práctica promovidas por construcciones discursivas cargadas de elementos históricos, políticos, culturales y sociales. Es así, que el presente articulo quiere generar un ejercicio critico-reflexivo, que evidencie desarticulaciones y paradojas que puedan ser las detonantes para propiciar imaginarios al interior de esta manifestación. Supuestos que intervienen y afectan de una u otra forma las condiciones que pueden incrementar las indagaciones creativas de esta experiencia danzaria en la ciudad.
\end{abstract}

\section{PALABRAS CLAVES}

Folklore, danza folklórica, danza folklórica de proyección, creación, noción, práctica, danza, proyección.

\section{BOGOTAPI IMASA MUIURIGTAKUNA TUKUIPI IUIARISPA SUMAIACHIG}

\section{SUGLLAPI}

Ñugpamandata muiurikuna tiarkakuna charami sinchiachiri mana tukuringachu Chasa sugkunapas tiangakunami muirigkuna imasami Ñugpamanda karkakuna chasa, chiwanmi Kunaura munari mana chingarichu imasa kaugsai iukarkakuna ñugpata chasa kaugsai iukarkakuna ñugpata chasa kasawan tukui ciudadpi munari kawachinga chara kausa kagta muiuriikuna.

IMA SUTI RIMAI SIMI:

Imasa muiurigtakuna, iuiarispa, imasa muiuringapa munanakugta.

\section{FOLK DANCE IN BOGOTA: BROODING REFLECTIONS}

\begin{abstract}
The creation in the folk dance apparently comes into continuous states of resistance. Phenomenon that is attributed to dissociation generated in the circulation of its meaning as a concept and also to contradictions that permeate their practice as folk dance genre. In response to this, you can show ambiguity between concept and practice promoted by discursive constructions full of historical, politicians, cultural and social elements. The present article wants to generate a critical - reflexive exercise, as evidence of dislocations and paradoxes that may be the trigger to encou rage imaginary within this demonstration. Assumptions involved and affect one way or another conditions that may increase the creative investigations of this dance company experience in the city .
\end{abstract}

\section{KEYWORDS}

folklore, folk dance, folk dance projection , creation, idea , practice, dance, projection 


\title{
LA DANSE FOLKLORIQUE A BOGOTÁ: CREUSANT DES RÉFLEXION.
}

\begin{abstract}
RÉSUMÉ
La création dans la danse folklorique semble entrer dans des états continus de résistance. Phénomène qui est affecté de dissociations engendrées par la circulation de sa signification comme notion et, également, à des contradictions qui imprègnent sa praxis comme genre de danse. Considérant cela, on peut mettre en évidence des ambigüités entre le concept et la pratique promue par des constructions discursives chargées d'éléments historiques, politiques, culturels et sociaux. Ainsi, le présent article souhaite produire un exercice critico-réflexif qui mette en évidence les désarticulations et paradoxes qui peuvent être des détonateurs afin de favoriser les imaginaires au sein de cette manifestation. Présupposés qui interviennent et affectent d'une façon ou d'une autre les conditions qui peuvent augmenter les recherches créatives de cette expérience de la danse dans la ville.
\end{abstract}

\section{MOTS CLÉS}

Folklore, danse folklorique, danse folklorique de projection, création, notion, pratique, danse, projection.

\section{DANC̣A FOLCLÓRICA EM BOGOTÁ: CAVANDO REFLEXIC̣ÕES}

\begin{abstract}
RESUMO
A criação na dança folclórica, aparentemente, entra em estados contínuos de resistência. Este fenômeno é atribuído à dissociação gerada na circulação do seu significado como um conceito e também a contradições que permeiam sua prática como o gênero. Em resposta a isso, você pode mostrar a ambigüidade entre conceito e prática promovida pelas construções discursivas cheia de elementos históricos, políticos, culturais e sociais. Assim, o presente artigo tem como objetivo gerar um exercício crítico-reflexiva, como prova de luxações e paradoxos que podem ser o gatilho para incentivar dentro desta demonstração imaginária. Pressupostos envolvidos e afetam de uma forma ou outra condições que podem aumentar as investigações criativas desta experiência companhia de dança na cidade.
\end{abstract}

\section{PALAVRAS CHAVES}

Folclore, danças folclórica, dança folclórica de projeção, criação, noção, prática, danças, projeção.

Recibido 01/08/2015

Aceptado $31 / 08 / 2015$

DOl: http://dx.doi.org/10.14483/udistrital.jour.c14.2015.2.a03 


\section{Creación, arte y paradoja}

\section{A propósito de la danza folclórica}

Hablar de danza folclórica es entrar en la dimensión del folclor, asumido por la mayoría de estudiosos como lo que ha sido enseñado, transmitido: Derivado de las palabras anglosajonas folk (pueblo) y lore [saber], etimológicamente significa "saber del pueblo". Este término, nacido con William J. Thomas en el ámbito de los estudiosos y aficionados a las "antigüedades" en 1846, no podía contemplar en sus inicios los cambios de sentido y uso que iba a sufrir durante su movilización en la historia, que irían a resultar fundamentales en su circulación y conformación como concepto abigarrado.

En la noción de folclor convergen facetas o significados tanto conservadores como progresistas. Las constantes renovaciones de tales significados pueden explicar el surgimiento de nociones como cultura popular tradicional (planteamiento latinoamericano que intentó relegar a un segundo plano el eurocentrismo o anglosajonismo inherente a la voz originaria) o patrimonio cultural inmaterial (instituida por la UNESCO).

Probablemente 'folclor' sea solo un término anglosajón veterano que con rapidez se propagó en un sentido confuso, tanto para dominar una "nueva" rama de conocimiento, como para establecer sistemas adecuados afines a su objeto de estudio o práctica en la época de su surgimiento. Sin embargo, hay que reconocer que 'folclórico' sigue siendo un adjetivo que enmarca toda una propuesta del hacer y el entender, por lo menos en ciertas danzas y músicas en la actualidad. Un ámbito que se considera parte importante del proceso de aprendizaje humano y fuente significativa de información para la historia.

Atendiendo a esto, la palabra folclor mantiene un gran andamiaje en la actualidad ${ }^{1}$. Se puede entender que al hablar de folclor no solo se hace referencia a lo antiguo o lo rural, a una supervivencia de algo o a una ciencia que estudia ese algo, sino también a lo que transita en manifestaciones vivas, tanto rurales como urbanas. La cuestión es entender este fenómeno de acuerdo con la época y el contexto donde se revisa.

El folclor en la actualidad asume una triple condición y funcionalidad: 1. La de cultura popular tradicional, planteada como folclor-vida' ${ }^{2}$, es decir, las manifestaciones funcionales, tradicionales; la cultura folclórica como tal. 2. La ciencia, entendida como una disciplina de estudio con creciente inclinación antropológica, que establece métodos científicos propios y estructuras de sistematización claras (muchos la designan con mayúscula: Folclor o Folclorología). 3. La proyección folclórica, entendida como las reinterpretaciones, producciones y reelaboraciones que se transmiten por medios "mecánicos" con objetivos expositivos o artísticos.
Por su lado y como coyuntura, la danza folclórica como concepto también se moviliza de manera ambigua en la actualidad. Puede que su apellido "folclórica" sea el que condicione esta dificultad para establecer una definición clara o bien delimitada, pues en el ambiente también circulan otras nociones como danza autóctona, danza típica y danza tradicional, equivalentes a la primera. Complicaciones que sin duda son promovidas por el mismo piso movedizo que la sustenta. Sin embargo, todo el mundo habla de "danza folclórica". Hay festivales de danza folclórica, propuestas didácticas sobre danza folclórica, grupos de danza folclórica y bailarines de danza folclórica. La pregunta sería: ¿A que se refieren cuando disertan sobre esta práctica en la actualidad?

Para empezar, se podría acoger la motivación teórica que refiere el folclor a una experiencia espontánea comunitaria, acuñando la expresión 'danza folclórica' para todas las manifestaciones dancísticas (saber dancístico) desarrolladas de forma espontánea en comunidades (pueblo) en estrecha relación con lo rítmico-musical, y que han sido traspasadas de generación en generación como parte de experiencias simbólicas espirituales, materiales y sociales.

1. Más que una práctica o una ciencia, el folclor se relaciona con la consolidación de la identidad nacional, gestándose en los sentidos de pertenencia que articulan estas prácticas, en la producción de significados y en las relaciones que estos atienden a los procesos de identidad y su movilidad geográfica específica. Es así que el folclor colombiano determina los modos de hacer y ser del colombiano, sus prácticas, incluida la danza, constituyendo un discurso, una imagen de país y de sus diversas regiones. Inventada o no, esa imagen resulta importante para matizar un sentimiento de pertenencia, una cierta emoción ante la herencia de los antepasados, que muchas veces agita el fervor tradicionalista, a tono con intereses morales, estéticos e incluso políticos.

2. Se refiere al folclor que asume los conocimientos y las manifestaciones culturales (creencias, costumbres, danzas, músicas, comidas, etc.) articuladas por una identidad comunitaria, desarrollada en territorios específicos (no necesariamente demarcados por la geografía o el clima). Esos conocimientos y manifestaciones culturales son transmitidos de generación en generación, asumidos, asimilados, reinterpretados e impulsados de manera colectiva, estableciendo rasgos afines e identificables, permeados por constantes cambios simbólicos según el contexto, la memoria, la necesidad inmediata o el propósito del transmisor. 

de práctica. Este movimiento establece repertorios y obras que son producidas, circuladas e impulsadas a su vez por estímulos estatales que incitan el desarrollo de esta dinámica danzaria. Bogotá, entonces, asume la danza folclórica como aquella práctica organizada que construye coreografías para un espectador a partir de elaboraciones e interpretaciones de los elementos folclóricos. Es por esto que la danza folclórica se edifica allí a partir de referentes identificables: Autores que recolectaron observaciones, impulsaron documentos, compendios y cartillas coreográficas desde donde se determinaron posiciones que posteriormente fueron apropiadas y masificadas. Autores, hoy ${ }^{4}$ llamados maestros, como Jacinto Jaramillo o Delia Zapata Olivella; creadores que son la columna vertebral fundamental en los constructos coreográficos de la mayoría de grupos en la capital.

Acogiendo esta condición, se podría decir que estamos hablando de perspectivas danzarias realizadas al margen del fenómeno folclórico espontáneo del que habla Abadía. Es así que puede tratarse en realidad de una danza folclórica de proyección. Carvalho Neto (1965: 126) llama a esto proyección estética, pues "se caracteriza por un cambio de portadores, un cambio de motivación, un cambio de función, un cambio de formas y un cambio de aprendizaje": Una representación que "al pasar a [otras] manos pierde la función específica, pues la motivación que la determina ahora es otra. En consecuencia, pierde también su forma, ya que a un cambio de motivación y de función corresponde casi siempre un cambio de forma". Se podría entender entonces que la danza folclórica (DF) que se evidencia en la capital es en realidad una de proyección, pues desarrolla en su práctica cambios sustanciales en las maneras simbólicas y de transmisión, especialmente si el objetivo es presentar $^{5}$ ante un público (que no se involucra en la construcción] una propuesta danzaria. La danza folclórica de proyección (DFP) comprende construcciones coreográficas que en mayor o menor medida acogen elementos del fenómeno folclórico en sí. Desde ella, se propician expresiones artísticas que re-elaboran y re-significan formas folclóricas mediante procesos cinético-estéticos, atendiendo al contexto y al objetivo escénico que se desea lograr.

Cerrando esta parte, y aunque quedan varias cosas por resolver al respecto de esta dualidad conceptual, se podría decir que la noción de DFP está eclipsada por la de DF en la ciudad. Se mezclan o se confunden los propósitos de cada una. Esta ambigüedad se ve reflejada no solo en los discursos y en la circulación de las nociones desde la teoría, sino también en la praxis creativa, la circulación artística y en los debates que se suscitan dentro de la comunidad danzaria.

Hay que decir, por otro lado, que esta es una práctica danzaria importante, que desarrolla e implementa conocimientos técnicos, corporales, musicales, coreográficos, estructurales, escénicos y de creación en general; que promueve experiencias y consolida estructuras en las maneras de hacer en este género dancístico heterogéneo en Bogotá.

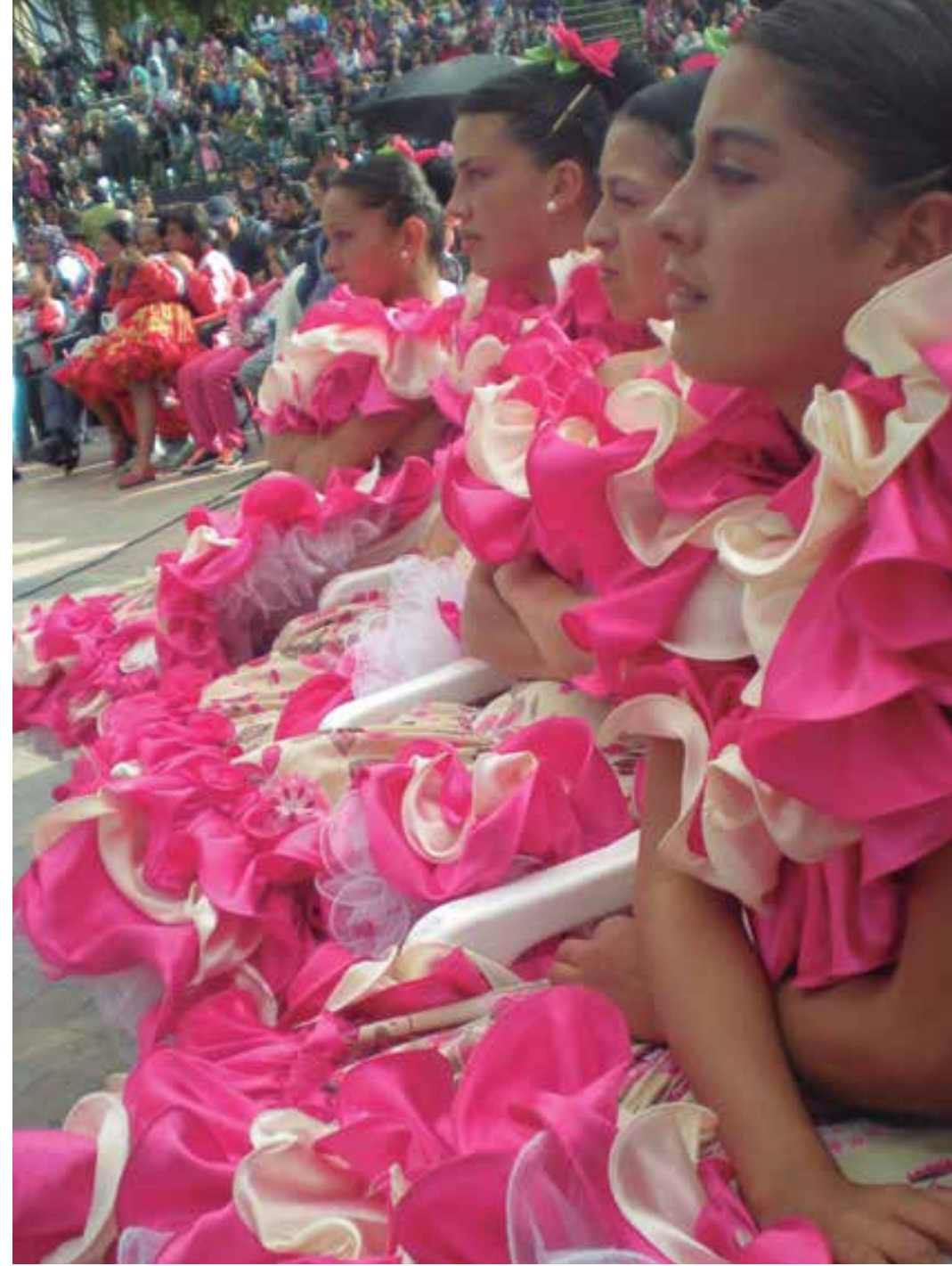

- Archivo Personal de Karina García. Festival de la Colombianidad - Tocancipá

4. Cabe mencionar que en la actualidad existen diferentes estrategias "alternativas" para edificar los procesos creativos en la danza folclórica bogotana. Un ejemplo de esto son los grupos de danza que emergen de procesos académicos (universidades) los cuales amplían sus búsquedas argumentativascreativas fuera de estos referentes identificables, fomentando prácticas de laboratorio y construcción colectiva (situación que empieza a reconocerse solo en los últimos años].

5. En palabras de Zárate: "Por lo que exponen todos los estudiosos del tema, nada que involucre la enseñanza sistemática, organizada, intencional, puede ser una práctica folclórica. De esto ha de deducirse lo imposible de calificar como folclóricas las creaciones de la persona culta aunque use en su creación elementos de este carácter y menos de calificar como folclóricas las prácticas que hacen las personas cultas de manifestaciones que pertenecen al folklor y que ellos han tratado de imitar, sobre todo porque cada una de esas demostraciones han sido resultado de ensayos organizados, sistemáticos para alcanzar la forma que un determinado director considere óptima, condiciones estas, que son la negación de lo que es folklor" (Danneman et al., 1975: 149- 150). 
Es claro que muchos hacedores de danza construyen sus discursos dotando de significado su producción artística con argumentos ligados al rescate de la tradición. Estos esquemas un tanto nostálgicos en ocasiones niegan otras formas de producción/tratamiento de las tradiciones danzarias. Cabría preguntarse, ante tales posiciones, si en verdad son necesarias estas disertaciones, pues estamos hablando de exponer/comunicar escénicamente -artísticamente-, una práctica que acoge cualquier apropiación o motivación para un desarrollo creativo ${ }^{7}$.

Es una cuestión paradójica, sobre todo cuando hay instituciones como la UNESCO, que en 1972 empieza a generar convenciones sobre la protección del patrimonio cultural y natural, promoviendo una angustia sobre ese "folclor" que debe entrar y circular como "Folclor" (pues la única manera de que no se pierda es reconociéndolo y consignándolo). Queriéndolo o no, se propicia un cierto proceso de homogenización. Se inventa un valor asociado a esa danza folclórica compilada, mientras que la danza folclórica viva, en su foco original, puede quedar en condición subalterna. Esto promueve aun más ese

\section{De la paradoja y la creación}

Entendiendo entonces que la DFP tiene como fin proyectar, es decir, exponer una propuesta dancística a partir de comprensiones fomentadas desde el folclor (la práctica viva), el folclor (la investigación científica) y otras reinterpretaciones, se podría decir que su desarrollo creativo como práctica artística es inagotable.

La cosa se complica cuando argumentos estereotipados de lo "colombiano", lo "típico" y la eterna riña entre lo tradicional y lo contemporáneo se cruzan en esta práctica danzaria. Están, por ejemplo, los argumentos que acompañan a la DF/DFP construidos desde ese interés de salvaguarda a ultranza. Aquellos que acogen los compendios y las sistematizaciones generadas por los "maestros" compiladores como la "danza folclórica verdadera", como la estructura absoluta, aquella que debe mantenerse, custodiarse y circularse como danza que apropia el sentimiento identitario del pueblo colombiano. También están los otros, los que se movilizan desde pensamientos renovadores e innovadores, pues entienden esta danza "tradicional" como una construcción que se moviliza constituyendo estrategias y estructuras danzarias propias de la actualidad que las asume, pues en ello estaría su verdadera identidad.

Los discursos nacionalistas, homogenizantes y contemporáneos hacen lo suyo agitando más el panorama. Sin duda, y como ya se había planteado, es necesario revisar los sentidos utilizados para tal o cual noción.
6. La DFP acoge varias herramientas compositivas, entre ellas las que se desarrollan y construyen a partir de referentes identificables de autores que recolectaron observaciones y anécdotas dentro de determinados registros. La cuestión es de designación, pues empieza a establecerse y a movilizarse con fuerza una llamada "danza folclórica" que involucra no solo una enseñanza sistémica, organizada e intencional, sino que evoca construcciones desarrolladas a partir de discursos delimitados, referencias precisas y objetivos más ligados a la exhibición. El punto es que en la actualidad hay un debate que intenso, por su naturaleza contradictoria, entre esa "danza folclórica" y la "danza tradicional", aquella que se construye de manera espontánea y funcional, y es cohesionadora de experiencias comunitarias.

Pensar la DFP en la actualidad, teniendo en cuenta este antecedente, es pensar en una manifestación dancística que se construye a partir de coreografías que, a su vez, cumplen con unas condiciones y requisitos fijados por un autor; danzas construidas a partir de interpretaciones hechas por investigadores en el pasado, danzas parametrizadas y fijadas que se dan a conocer como aquellas que conservan "los rasgos auténticos" de manifestaciones "danzarias tradicionales", que preservan la "pureza" y que no se pueden transformar, ya que fueron concebidas dentro de los "valores" propios de cada región.

Es por esto que la llamada "danza folclórica" es concebida como una constitución repetitiva, situación que le da un carácter repelente, por llamarlo de algún modo, que fractura estructuras emergentes desde necesidades creativas que pretenden reacondicionar esta reiteración. Es necesaria la reubicación de relaciones entre el fenómeno folclórico y la proyección folclórica. La complejidad semiótica de las nociones aquí planteadas sugiere la necesidad de estudios más detallados. 
discurso tradicionalista que tanto se escucha en el ámbito danzario actual y que muchas veces limita las posibilidades de comunicación con otras maneras de hacer danza folclórica de proyección. Por otro lado, la danza folclórica de proyección (asumida por una determinada comunidad artística bogotana como danza folclórica) empieza a reconocerse en una dimensión netamente artística, pensando la danza como disciplina y el arte como necesidad expresivo-comunicativa. Es entonces cuando el lugar de enunciación cambia, y los procesos creativos, sin dejar el sesgo "preservador", empiezan a acoger las demandas del público, lo que lleva a reconfigurar repertorios siguiendo cánones estéticos no propiamente esencialistas, ni mucho menos estáticos. $Y$ es así que las danzas recopiladas y asumidas como auténticas entran en un proceso de reconfiguración pensado para las necesidades de circulación. La búsqueda de técnicas para enriquecer el movimiento periférico y proyectivo entra a ser parte de las construcciones coreográficas. Algunos coreógrafos, por su lado, mantienen estructuras bastante conservadoras. Otros se arriesgan a reanimar esas formas del pasado con pinceladas tenues que acentúan lo que se quiere proyectar. Otros más, por el contrario, recomponen, re-estructuran y refinan, pensando en un producto dinámico, versátil y lleno de sorpresas para un público exigente. Situaciones que poco a poco van empoderando modelos de virtuosismo y espectacularidad, generando más contradicciones. Muchas posiciones persisten y consolidan una resistencia ${ }^{8}$ frente a aquella mal llamada danza folclórica (danza folclórica de proyección). Lo paradójico está en que no solemos percatarnos de que tanto los "tradicionales" como los "contemporáneos" del folclor danzario han aceptado y asimilado el sentido espectacular y las dinámicas del mercado a él asociadas. Puede que una vez más estemos ante esa "historia progresiva de la danza espectacular como un relato determinado por la búsqueda de la autonomía estética" (Tambutti, 2008: 11).

Evidenciamos una práctica artística que se renueva (se contradice, se tensiona, avanza y retrocede), aunque en muchas de sus circunstancias sigue asumiendo una carga simbólica importante respecto a la custodia de tradiciones y costumbres. Aquella que desde el acceso a testimonios históricos también encuentra la posibilidad de emprender nuevas rutas con respecto a su imaginario actual.

Por otro lado, debemos pensar que como sociedad también necesitamos de esa danza folclórica de compendios y sistematizaciones, "tradicional", para movilizar una "identidad" construida. En palabras de Stuart Hall, "El antropólogo francés Claude LéviStrauss, argumenta que los grupos sociales imponen significados a su mundo, ordenando y organizando las cosas en sistemas clasificatorios". Es así "Que las culturas estables requieren que las cosas permanezcan en un lugar asignado. Las fronteras simbólicas mantienen las categorías 'puras' dando a las culturas significado e identidades únicas" (Hall, 2010: 421).
Los debates que se dan alrededor de la danza folclórica de proyección, sobre su pureza y proceso de creación, han estado siempre presentes. Sin embargo, la ambigüedad y el temor a la confrontación hacen que esta discusión carezca muchas veces de forma y de fondo.

Hablar de creación en la danza folclórica de proyección es entrar en otro régimen de la verdad, como diría Foucault. Asumimos verdades históricas desde el Folclor, empoderamientos con respecto al cómo se debe hacer, ejecutar o vestir una danza. Verdades que suprimen el acto creador que impulsa el arte, generando una pelea continua entre el ser y el deber ser de la danza folclórica de proyección en el contexto actual. La pertinencia abandona la causa: muchas veces prima la forma ya establecida sobre la necesidad transformadora que hace vital a la danza.

Podrá haber un desenlace, sin duda; cuando la danza folclórica de proyección empiece a verse no solo como manifestación dancística recopilada y sistemática, sino como expresión artística propositiva. Es probable que ese acto creador también esté sujetado a la negación $n^{9}$ misma de la tradición como acción continua, tal como lo reflexiona Hall (2012: 339): "La mayoría de nosotros reconoce que nuestras identidades han cambiado con el tiempo, pero tenemos la esperanza, o la nostalgia, de que cambien tan lentamente como los glaciares".

Se le podría plantear entonces a esa "danza folclórica repelente hoy constituida, normalizada y transitada por muchos en la ciudad", que desde su condición de práctica expositiva (no tanto como manifestación "típica, pura"] puede ampliar su visión

7. La creación en la danza folclórica, al parecer, entra en estados continuos de resistencia. Resiste a los discursos esencialistas, resiste a las categorizaciones, resiste a las atribuciones estéticas, resiste a las dicotomías históricas, resiste a los objetivos mercantilistas, resiste a los objetivos tradicionalistas. Y, a decir verdad, más que resistir se adapta, brindando un lugar de reflexión que espero indagar a profundidad en otro momento.

8. Manuel Zapata Olivella puede ser un ejemplo de resistencia con respecto a este tema cuando dice que "los colombianos participamos en forma creadora, aunque no siempre lúcida y libremente, en la edificación de nuestra nacionalidad (...) Situaciones neocolonizadoras que se quieren presentar como los nuevos procesos de 'globalización', en los que los valores se fabrican y planifican con objetivos a veces netamente comerciales" (1974: 178).

9. Hablamos de tradición, identidad y costumbres de forma romántica y nostálgica, no hay riesgo de contemplar nuevas formas al respecto, evidenciándose un tipo de emancipación. Bien dice Zygmunt Bauman (2002: 21): "pocos individuos deseaban liberarse, todavía menos estaban dispuestos a actuar para lograrlo". Desde este punto de vista, se puede decir que la creación en esta "danza folclórica repelente" está atravesada no solo por un imaginario histórico sino también por un miedo evidente respecto al cambio. 
al acto creativo, pues la creación es totalmente viable llena de recursos y caminos propositivos. El maestro Abadía, por ejemplo, estandarizó y sistematizó la danza folclórica. Sin embargo, dentro de sus argumentos se puede encontrar que la construcción coreográfica se puede desarrollar de manera subjetiva: "Coreografías organizadas por danzarines o aun por coreógrafos profesionales, y algunas de ellas han recibido la acogida y aun prohijamiento de las masas populares, como es el caso de La chiquinquireña, de Alberto Urdaneta, que ideó el coreógrafo Jacinto Jaramillo en 1938" (Abadía, 1983: 297).

Entonces, muchas coreografías hoy llamadas tradicionales son construcciones subjetivas de coreógrafos. Propuestas creativas e invenciones logradas desde objetivos estéticos proyectivos. Es así que cualquier coreógrafo puede lograr este tipo de ejercicio, observando y desarrollando un trabajo de movimiento desde la pertinencia y compromiso con respecto al fenómeno folclórico.

Teniendo en cuenta esto, el acto creador en la danza folclórica de proyección ${ }^{10}$ también se puede convertir en una herramienta para abrir espacios simbólicos vitales a la tradición. Desde este punto de vista, se está hablando entonces de un consenso y una negociación entre creación y folclor, actualizando el balance entre pasado y presente.

Para finalizar se puede decir que la danza, como la vida misma, es dinámica, se moviliza, se regula, pero al mismo tiempo motiva nuevas experiencias. La creación se convierte en un ejercicio fundamental dentro de los propósitos de la danza misma. Los desplazamientos que se sublevan frente a esas sistematizaciones heredadas están impulsados por cuerpos urbanos del siglo XXI, que reflexionan/revisan los planteamientos decimonónicos.

Es así como, con el paso de los años, los cuerpos expresivos han ido transformándose, entretejiendo culturas, momentos y épocas que confluyen en 'cuerpos nuevos', heteróclitos, en los que ocurre la simbiosis de lenguajes y conocimientos que se adaptan y readaptan en sí mismos, se reacomodan en espacios y tiempos, originando nuevos códigos comunicativos que constituyen cultura e identidad por cuanto se convierten en significantes. Recuperar la expresión y la percepción del mundo desde el cuerpo permite recuperar al ser humano holístico protagonista de su historia y su cultura (Plata, 2011: 60).

Atendiendo a esto, la tradición también está en una construcción viva en la danza.

Avanzar en el campo de la creación en la danza folclórica de proyección entonces, es entender el vínculo que une la creación, la danza y la tradición: el cuerpo. En palabras de Hilda Islas:

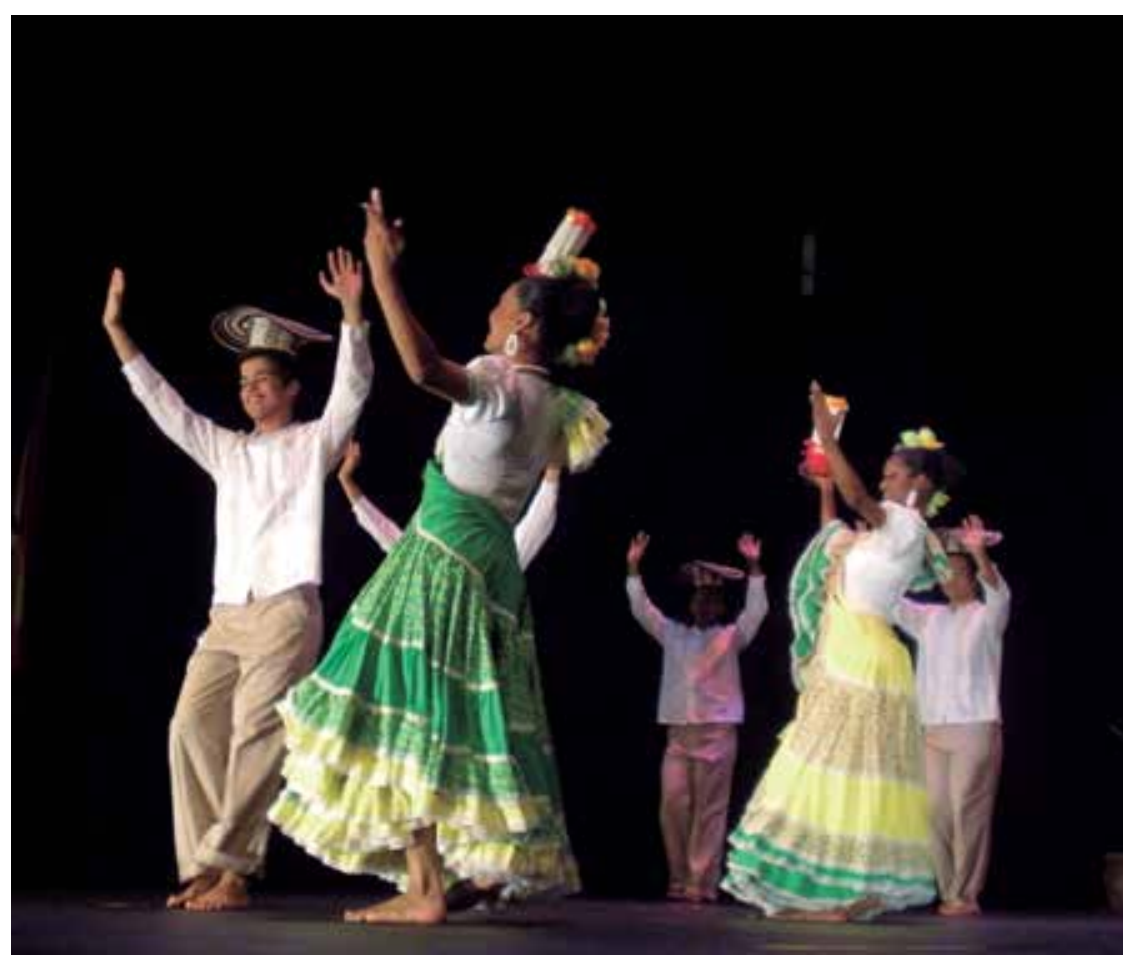

$\Delta \quad$ ARCHIVO CIOFF Colombia - III Congreso Nacional e Internacional de Folclor - Cartagena

El hacer corporal, como se ha visto, participa de una transmisión y aprendizaje cultural que no pasa en esencia por las vías discursivas y racionales. Aprender a moverse y aprender a cambiar los patrones de movimiento, tanto en las técnicas cotidianas como en las extracotidianas, además de un hecho culturalmente normado, es un fenómeno psicológico y psicomotriz con una lógica propia. Es decir, si bien el movimiento es una producción social, también es un fenómeno individual e interior (Islas, 2001, p. 30).

La danza folclórica de proyección en Bogotá es sin duda un fenómeno versátil, lleno de posibilidades. Coreógrafos y directores conservadores, reformistas y progresistas encuentran en esta ciudad su espacio, cada uno con su certeza, cada uno con su justificación válida. La cuestión, tal vez, sea dejar de pensar en las formas (danza folclórica tradicional, de proyección o ballet folclórico) para iniciar una profunda reflexión que permita reconocer la danza folclórica de proyección como una manifestación importante, llena de dinámicas propias en la cultura y la danza de la ciudad.

\footnotetext{
10. Sería importante decir también que se habla de una "danza folclórica" (danza folclórica de proyección para esta reflexión) que fue construida con fines escénicos. Para ella los valores ancestrales pierden relevancia, aunque a nivel discursivo se diga otra cosa. La otra danza, la danza folclórica sin comillas, la que se da de manera espontánea en los pueblos, la que guarda la tradición y la que surge sin objetivos expositivos, sigue su curso vital en las comunidades.
} 


\section{Referencias}

Abadía Morales, Guillermo (1983). Compendio general de folclor colombiano. Bogotá: Biblioteca Banco Popular.

Barrios Alday, Patricio (1993). Folclor y escenario. Chile: Agencia de Publicidad Vía Magín.

Bauman, Zygmunt (2002). Modernidad Liquida. Argentina: Fondo de Cultura Económica.

Bovio, Arturo Rico (1998). Las fronteras del cuerpo. Crítica de la corporeidad. Quito: Editorial

García Canclini, Néstor (1989). Culturas híbridas. México: 2009 Primera Edición Formato Debolsillo.

Carvalho-Neto, Paulo (1965). Concepto de folclor. México: Pormaca.

Cortázar, Raúl Augusto (1949). El carnaval en el folclor calchaqui con una breve exposición sobre la teoría y la práctica del método folclórico integral. Buenos Aires: Editorial Sudamericana.

(1954). El folclor y su caracterización. Lima: Comité Interamericano de Folclor, año II, No. 2.

Cortázar, Abadía, Aretz, Guevara, et al. (1975). Teorías del folclor en América Latina. Caracas: Instituto Interamericano de Etnomusicología y Folclor del CONAC, Biblioteca INIDEF 1.

Escobar, Z. Cielo Patricia (1998). iA bailar Colombia!: danzas para la educación básica. Bogotá: Cooperativa Editorial Magisterio.

(1997). Danzas folclóricas colombianas. Guía práctica para la enseñanza y aprendizaje. Bogotá: Cooperativa Editorial Magisterio.

Hall, Stuart (2010). Sin Garantías. Popayán: Instituto de estudios sociales y culturales Pensar. Universidad Javeriana. Envión Editores.

Islas, Hilda (2001). De la historia al cuerpo y del cuerpo a la danza. México: Conaculta.

Martín, Alicia (2005). Folclore en las grandes ciudades. Argentina: Libros del Zorzal.

Martínez, Gilberto (2005). Danza Tradicional Colombiana en Memorias de danza, tomo III. Bogotá: IDCT.

Plata, Hanz (2010). Tránsitos de la investigación en Danza. Bogotá: Encuentros y reflexiones en torno al saber del cuerpo, la creación, la tradición y la memoria. Parte 1: 2010 Instituto Distrital de las Artes -IDARTES.

Quintero Rivera, Ángel (2009). Cuerpo y cultura. Madrid: Iberoamericana-Vervuert.

Redfield, Foster, Chertud et al. (1991). Introducción al folclor. Buenos Aires: CEAL, Centro Editor de América Latina, Colección Los Fundamentos de las Ciencias del Hombre.
Tambutti, Susana (2008). Itinerarios Teóricos de la Danza. Chile: Aisthesis, No. 43, Pontificia Universidad Católica de Chile Santiago.

Viana, Luis Díaz G. (2003). El regreso de los lobos. La respuesta de las culturas populares a la era de la globalización. Madrid: CSIC.

Zapata Olivella, Manuel (1974). El hombre colombiano. Bogotá: Canal Ramírez.

Zea, Francis Lucía de (1991). Manual de Coreografías de la Zona Andina. Bogotá: Patronato Colombiano de Artes y Ciencias.

Fundación Joaquín Piñeros Corpas. 
Dis wa

cort-

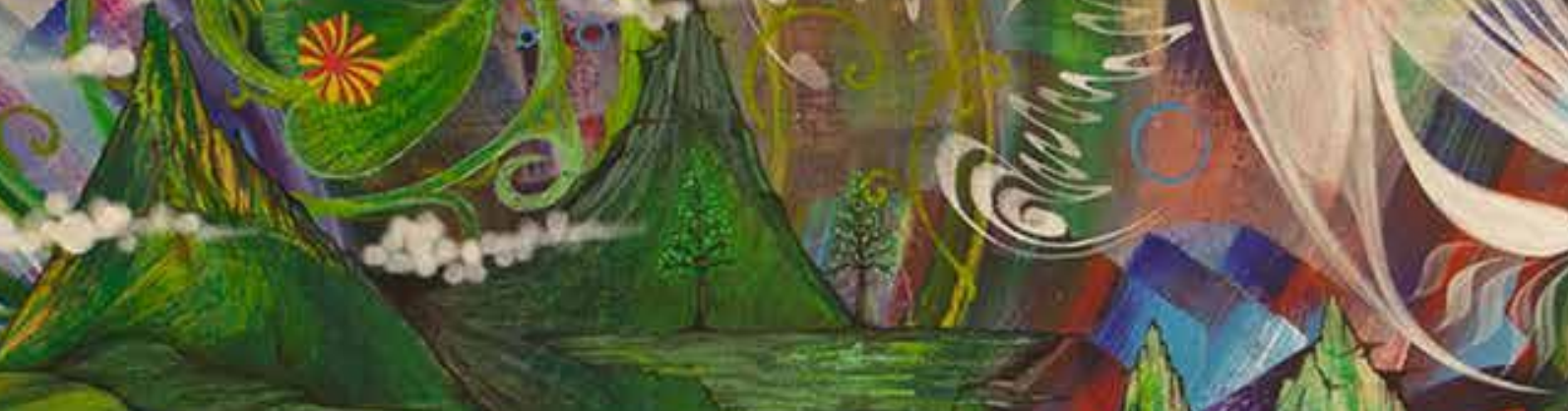

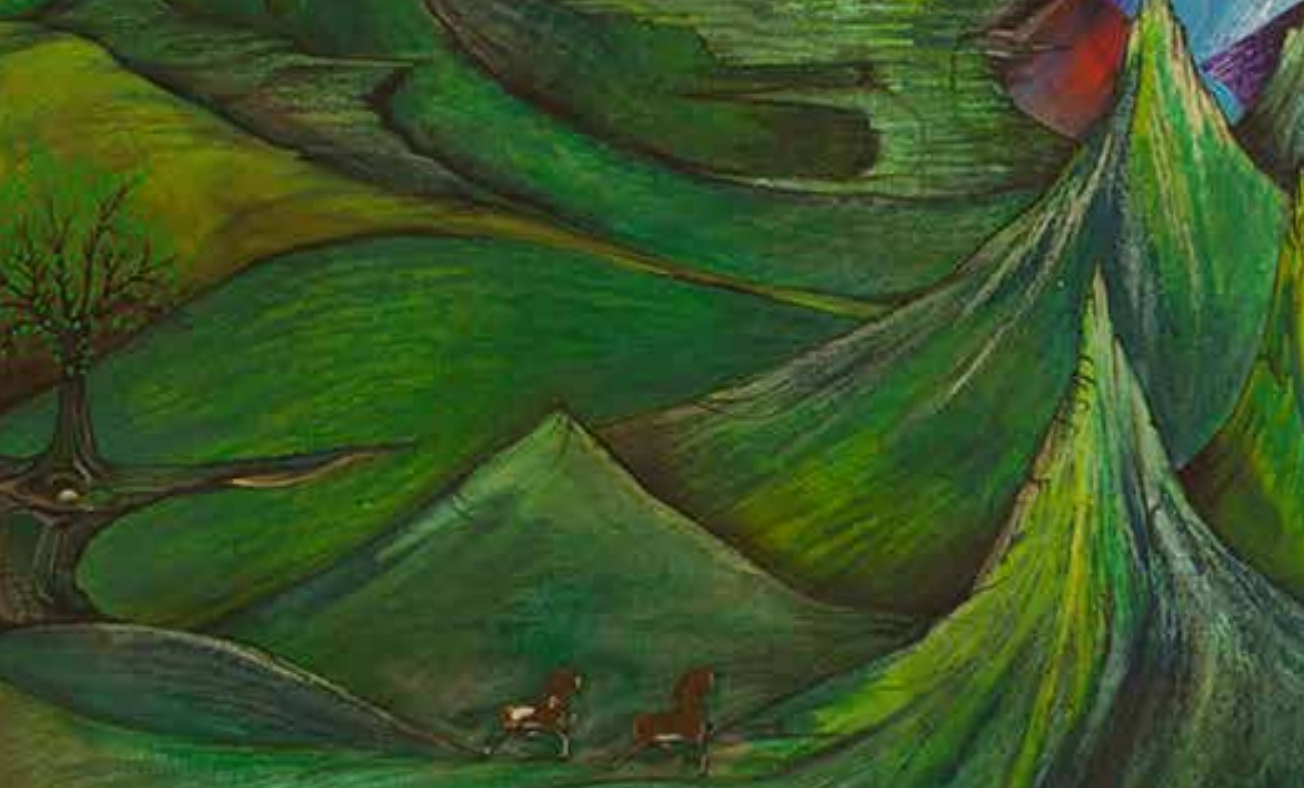

if

(a)

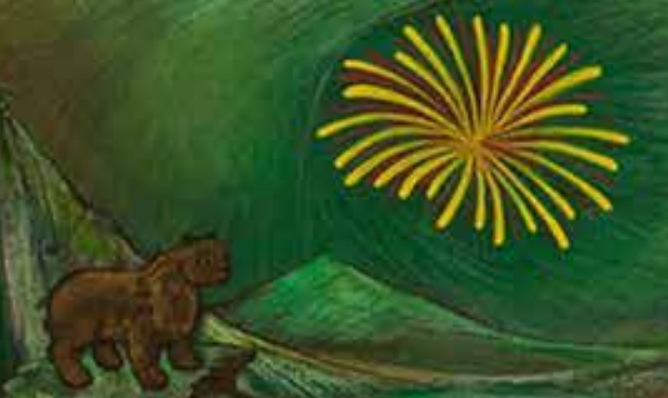

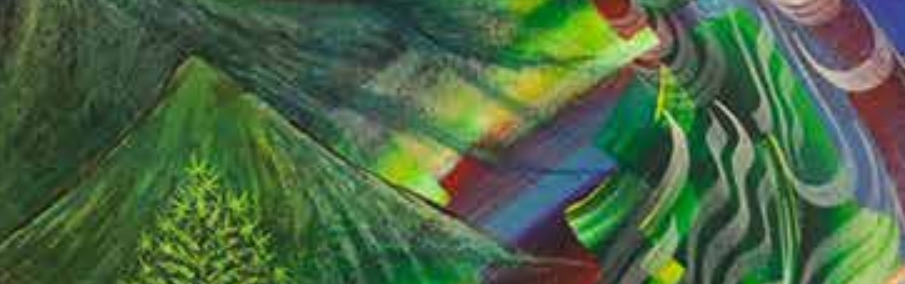
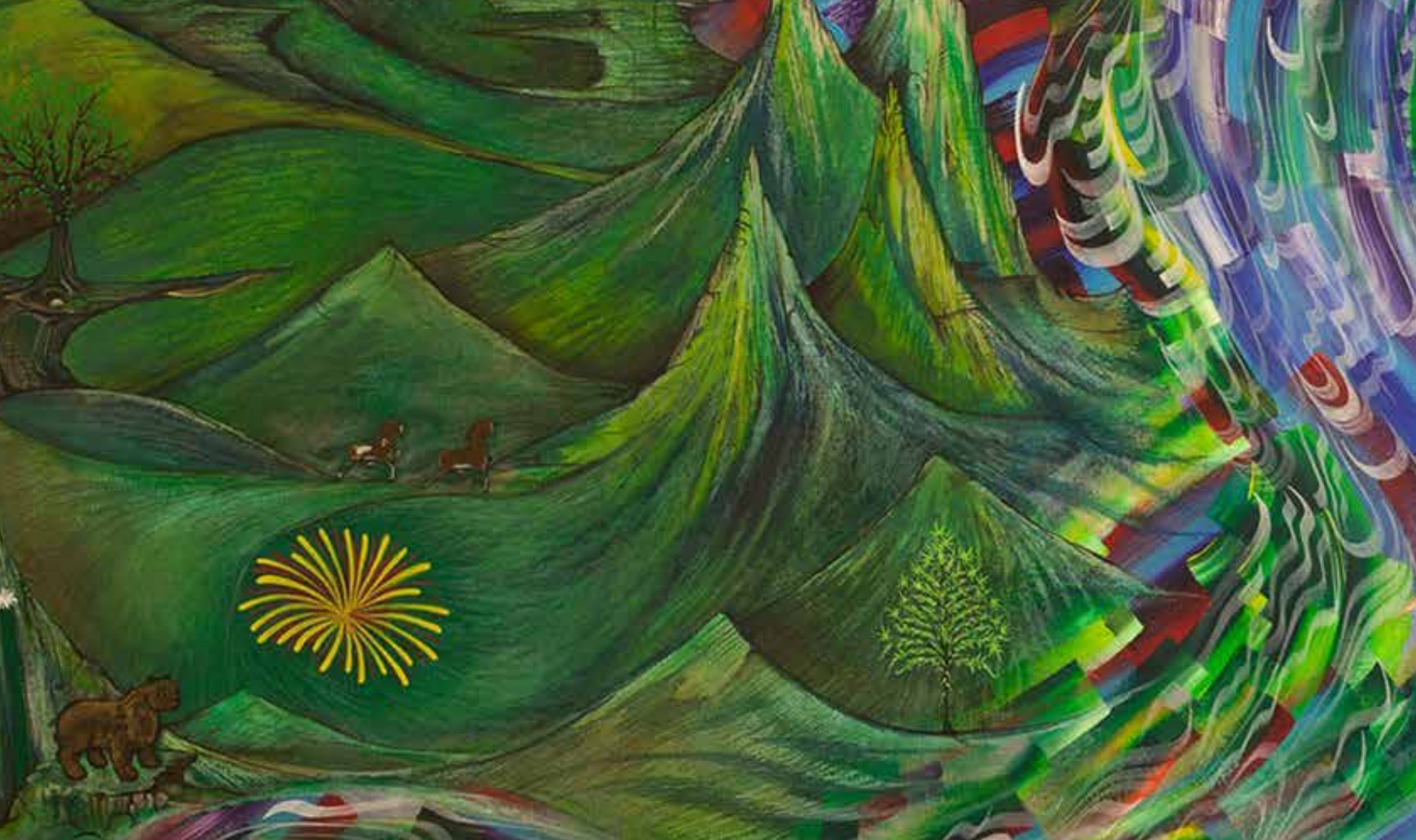

$$
\begin{aligned}
& \text { ce } \\
& \text { nowe } \\
& \text { 1. } \\
& =\sqrt{7}-\sqrt{3} \\
& \text { re }
\end{aligned}
$$

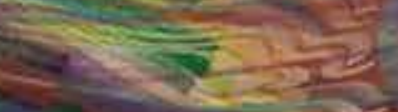


ars 